\title{
Risk Management of Baijiu Sustainable Supply Chain in China
}

\author{
Xianglan Jiang, ${ }^{1,2,}$, Ping Qing ${ }^{3}$, Yao Yang ${ }^{4}$ \\ ${ }^{1}$ Management School, Sichuan University of Science \& Engineering, Zigong, 643000, China \\ ${ }^{2}$ School of Economics and Management, University of Electronic Science and Technology of China, \\ Chengdu, 611731, China \\ ${ }^{3}$ School of Economics and Management, Chengdu Sport University, Chengdu, 610041, China \\ ${ }^{4}$ Business School of Sichuan University, Chengdu, 610064, China
}

Keywords: Baijiu Industry, Sustainability, Supply Chain, Risk Management, Decision Making

Abstract: Rapid market changes aimed at sustainability have led to supply chain risks and uncertainties in the Chinese Baijiu industry. This paper develops a systemic perspective of sustainable supply chain risk management in Baijiu industry in China. It explores sustainability-related supply chain risks in Baijiu industry. Through literature review and expert opinion, 30 risks are identified first. The failure mode and effect analysis (FMEA) method is used to assess the relative importance of the selected risks. And the technology is applied to a real case study at a Baijiu company in Sichuan, China. Based on the study, risk treatment strategies are provided for all the risks in Baijiu supply chain. The results show that the top five most important risks are culture risk, product risk, moral hazard, partnership risk and financial crisis, and the least important risks are unhealthy working conditions, water quality risk and excessive working time. The research method of this article can provide practical value for other Baijiu companies, and also provide value for the supply chains of other industries.

\section{Introduction}

In recent years, supply chain risk management has become an essential issue for supply chain management ${ }^{[1]}$. Supply chain risk will affect the stability of the supply chain and reduce the overall competitiveness of the supply chain, then ultimately lead to huge losses of enterprises in the supply chain. Risk issue is an important problem that any enterprise must face at any state of development. In recent years, the risk events of global supply chain break out frequently, which has a great impact on global supply chain. Supply chain disruptions can have significant impact on a firm's performance ${ }^{[2]}$. For example, Zte supply chain disruption event in 2018, caused billions of lost for the whole supply chain. Tianjin warehouse explosion in 12th August 2015, caused massive economic damage, environmental pollution and negative social impacts. Another example was the 2012 liquor plasticizer scandal, which resulted in companies in the industry sector losing 32.7 
billion CNY in share value. The extended supply chains are more vulnerable, exposing organizations to higher levels of risk.

The pursuit of sustainability is increasingly recognized as an effective strategy to deal with some of the contemporary challenges facing global supply chains ${ }^{[3]}$. It leads to enhanced competitiveness and improved financial performance and generates moral capital for firms to mitigate the consequences of potential business risks. Baijiu (Chinese liquor) is one of the world's oldest distilled alcoholic beverages and plays a significant role in Chinese culture and Chinese people's daily life ${ }^{[4]}$. The Baijiu industry is a traditional unique industry that has played a very important role in the development of the Chinese economy, as it is not only a food product, but also important culture heritag $\mathrm{e}^{[5]}$.. Among all the industries and organizations, the liquor industry has enjoyed high growth rates in world. The Baijiu supply chain is one of the industries that have made great efforts to sustainable development. There are many uncertainties in Baijiu supply chain, and the uncertainties have created serious risks and challenges for the whole industry.

The intent of this paper is threefold. First, we develop a risk criteria system including three dimensions in Baijiu sustainable supply chain. Second, we propose a model to evaluate risks in Baijiu supply chain. Third, by applying the model to a real case study at a focal Baijiu enterprise in Sichuan, we hope to motivate policy makers to mitigate supply chain disruptions in Baijiu supply chain.

The rest of this paper is organized as follows. Section 2 summarizes a systematic literature review of sustainable supply chain risk management. Section 3 identifies the sustainable supply chain risk in Baijiu industry. Section 4 proposes a FMEA method. Section 5 provides a case study to discuss the results of this study and summarizes the managerial implications based on this case study. The conclusions are presented in Section 6.

\section{Literature review}

In this section, literature review is analyzed in the following two categories: sustainable supply chain risk management and stages of risk management.

\subsection{Sustainable Supply Chain Risk Management}

Growing global operations on one hand drive cost down substantially but on the other hand make the supply chain more vulnerable to numerous risks ${ }^{[3]}$. There is a growing concern with supply chain sustainability and risks, however, few researches have investigated the sustainable supply chain risk ${ }^{[6]}$. Some of them focus on financial risks and others are limited to specific factors ${ }^{[7]}$. Some consider that any risk management strategy is applicable to sustainability related risk research ${ }^{[8]}$. The traditional management dimension of supply chain risk is economic dimension. However, with enterprises, government, customer, and public concern with environmental protection and social responsibility, risk management has linked to the triple bottom line management. Foerstl et al. initiated such research in this field by developing sustainable supplier risk management ${ }^{[9]}$. Hoffman et al. studied sustainable related risks caused by supply chain issues $^{[10]}$. Pullman et al. considered triple bottom line and Brundtland definition, and divided risks 
into economic risk, environmental risk and social risk ${ }^{[11]}$. The report by United Nations Global Compact and BSR (2010)suggests that common sustainability-related risks for many industries are greenhouse gas emissions, natural disasters, accidents, energy consumption, packaging waste, environmental damages during logistics and transportation ${ }^{[12]}$.

In summary, the research on risk management of Baijiu enterprises is relatively rare, and papers on supply chain perspective are few. And there is no paper to analyze sustainability from the three dimensions of economic, environmental and social. These indicate that the supply chain risk management research in Baijiu industry is still immature. Therefore, Baijiu supply risk management has important theoretical and practical value for research.

\subsection{Stages of Risk Management}

A consensus exist that the main stages of risk management involve four sequential stages: risk identification, risk assessment, risk analysis, and risk treatment ${ }^{[3]}$. As shown in Figure1.

Risk identification: This is the first step where all possible supply chain sustainability-related risks are identified with tools such as checklist, taxonomies and risk mapping.

Risk assessment: Risk estimation, it is a statistical process that quantifies risk, including the probability of loss occurring and the severity of the loss.

Risk analysis: Risk assessment is based on the results of risk measurement to determine the risks that companies need to pay more attention to.

Risk treatment: Four major responses are suggested in the literature to control supply chain risks. These responses are linked to sustainability-related risks:

Avoid: It involves the avoidance of an activity that may lead to exposure to a risk.

Control: Making efforts to reduce the risk occurrence likelihood or its severity.

Share: Collaborating with other sector and transferring the risk effect to the outside of the organization.

Retain: Accepting possible damages (when the cost of each risk treatment strategy exceeds the possible risk costs.)

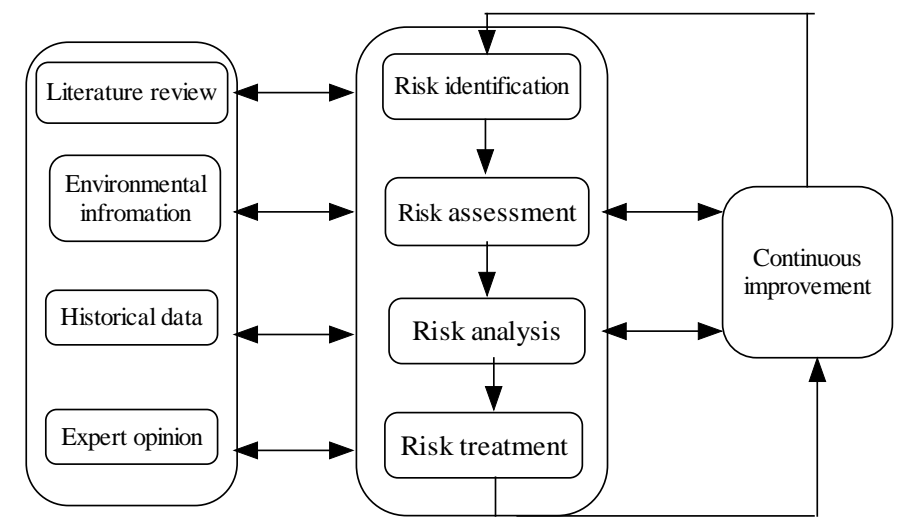

Figure 1: Stages of risk management.

Continuous improvement: It is the last step, which includes continuous monitoring of the effects of the strategies for responding to each risk, identifying risks, making the required changes in accordance with the dynamic nature of the risk management, and proposing new solutions. 


\section{Identification of Risks in Baijiu Sustainable Supply Chain}

According to literature review and expert opinion, the risks of Baijiu sustainable supply chain divided into economic, environmental and social three dimensions. Thirty risk factors are identified in this paper, as shown in Tabel 1. Economic risks include Price fixing accusations, Tax evasion, Boycotts, Supply volatility, Financial crisis, Legal risk/Litigations, Demand volatility, Product risk, Financial risk, Information risk, Partnership risk, Logistics risk, Management risk, and Globalization. Environmental risks include Environmental accidents, Pollution, Natural disasters, Smog, heat wave, droughts, Product waste, Non-compliance with sustainability laws, Carbon emissions, and Water quality risk. Social risks include Unhealthy working environment, Unfair benefits, Excessive working time, Pandemic, Brand image risk, Policy risk, Cultural risk, and Moral hazard.

Table 1: Risks in Baijiu sustainable supply chain.

\begin{tabular}{ll}
\hline Dimension & Criteria \\
\hline Economic & Price fixing accusations \\
& Tax evasion \\
& Boycotts \\
& Supply volatility \\
& Financial crisis \\
& Legal risk/Litigations \\
& Demand volatility \\
& Product risk \\
& Financial risk \\
& Information risk \\
& Partnership risk \\
& Logistics risk \\
& Management risk \\
& Globalization \\
& Environmental accidents \\
& Pollution \\
& Natural disasters \\
Smog, heat wave, droughts & Product waste \\
Nonironmential & Carbon emissions \\
& Water quality risk \\
& Unhealthy working environment \\
& Unfair benefits \\
& Excessive working time \\
& Pandemic \\
& \\
& \\
& \\
&
\end{tabular}


Brand image risk

Policy risk

Cultural risk

Moral hazard

\section{Proposed Methodology}

Failure mode and effects analysis (FMEA) is a widely used engineering technique for defining, identifying and eliminating known and/or potential failures, problems, errors and so on from system, design, process, and/or service before they reach the customer ${ }^{[13]}$. FMEA is broadly used as a reliability tool to recognize likely failures before they happen with the aim of reducing their risks. Since FMEA method is based on finding, prioritizing, and minimizing the failures, it has been broadly utilized in types of industrial areas ${ }^{[14]}$.

The risk priorities of failure modes are usually obtained by the risk priority number (RPN) base on FMEA method. It evaluates occurrence (O), severity (S), and detection (D), which is defined as: $\mathrm{RPN}=\mathrm{O} * \mathrm{~S} * \mathrm{D}$. Where $\mathrm{O}$ is the probability of the failure, $\mathrm{S}$ is the severity of the failure, and $\mathrm{D}$ is the probability of detection. For obtaining the RPN of a potential failure mode, the three risk factors are evaluated using the $1-10$ point scale described in Tables $2-4{ }^{[15,16]}$. The higher the assigned number is the higher the importance of the failure mode is with respect to the related index. With respect to the scores of RPNs, the failure modes can be ranked and then proper actions will be preferentially taken on the high-risk failure modes. RPNs should be recalculated after the corrections to see whether the risks have gone down, and to check the efficiency of the corrective action for each failure mode.

Table 2: Ratings for occurrence of a failure mode.

\begin{tabular}{cll}
\hline Rating & Probability of occurrence & Failure probability \\
\hline 10 & Extremely high: failure almost inevitable & $>1$ in 2 \\
9 & Very high: failure almost inevitable & 1 in 3 \\
8 & High: repeated failures & 1 in 8 \\
7 & High: repeated failures & 1 in 20 \\
6 & Moderately high: occasional failures & 1 in 80 \\
5 & Moderate: occasional failures & 1 in 400 \\
4 & Relatively low: relatively few failures & 1 in 2000 \\
3 & Low: relatively few failures & 1 in 15000 \\
2 & Remote: nearly impossible failures & 1 in 150000 \\
1 & Extremely low: nearly impossible failures & $<1 / 1500000$ \\
\hline
\end{tabular}


Table 3: Ratings for the severity of a failure mode.

\begin{tabular}{|c|c|c|}
\hline Rating & Effect & Severity of effect \\
\hline 10 & Hazardous without & Failure is hazardous, and occurs without warning. \\
\hline & warning & $\begin{array}{l}\text { It endangers the safety of Baijiu supply chain and } \\
\text { jeopardizes the reputation of enterprises. }\end{array}$ \\
\hline 9 & Hazardous with warning & $\begin{array}{l}\text { Failure is hazardous, and occurs with warning. It } \\
\text { endangers the safety of Baijiu supply chain and } \\
\text { jeopardizes the reputation of enterprises. }\end{array}$ \\
\hline 8 & Very high & $\begin{array}{l}\text { Supply chain is inoperable with loss of primary } \\
\text { function. The supply chain is inoperable, } \\
\text { customers are very dissatisfied. }\end{array}$ \\
\hline 7 & High & $\begin{array}{l}\text { Supply chain performance is severely affected but } \\
\text { functions. The supply chain may not operate, } \\
\text { customers are very dissatisfied. }\end{array}$ \\
\hline 6 & Moderate & $\begin{array}{l}\text { Part of supply chain is inoperable, customers feel } \\
\text { very inconvenient. }\end{array}$ \\
\hline 5 & Low & $\begin{array}{l}\text { Part of supply chain performance is degraded, } \\
\text { customers feel inconvenient. }\end{array}$ \\
\hline 4 & Very low & $\begin{array}{l}\text { Some parts of supply chain have problems, and } \\
\text { most customers find defects. }\end{array}$ \\
\hline 3 & Minor & $\begin{array}{l}\text { Some parts of supply chain have problems, and } \\
\text { half of the customers find defects. }\end{array}$ \\
\hline 2 & Very minor & $\begin{array}{l}\text { There are minor effects on some parts of the } \\
\text { supply chain, and few customers find defects. }\end{array}$ \\
\hline 1 & None & No effect \\
\hline
\end{tabular}

\section{Case Example}

The potential failure mode management of liquor company supply chain focuses on early warning and prevention, not afterwards control. The real case is a liquor company A in Sichuan, who faced fierce market competition pressure. In order to minimize risks in supply chain operations, it decided to develop an evaluation system which comprehensively analyzed the supply chain risks of the entire enterprise. Before conducting risk management, a special working group needs to be established. The group has 11 experts, including one general manager, two professors, two environmental experts, two suppliers, two customers, and two supply chain managers. All experts are high familiar with their respective fields and proficient in decision making. It uses FMEA method to manage risks. The framework is shown in Figure 2. 
Table 4: Ratings for detection of a failure.

\begin{tabular}{|c|c|c|}
\hline Rating & Detection & Likelihood of detection by design control \\
\hline 10 & Absolute uncertainty & $\begin{array}{l}\text { Design control does not detect a potential cause of } \\
\text { failure of subsequent failure mode; There is no known } \\
\text { mechanism for detecting the failure. }\end{array}$ \\
\hline 9 & Very remote & $\begin{array}{l}\text { Very remote chance the design control will detect a } \\
\text { potential cause of failure or subsequent failure mode }\end{array}$ \\
\hline 8 & Remote & $\begin{array}{l}\text { Remote chance the design control will detect a } \\
\text { potential cause of failure of subsequent failure mode }\end{array}$ \\
\hline 7 & Very low & $\begin{array}{l}\text { Very low chance the design control will detect a } \\
\text { potential cause of failure or subsequent failure mode }\end{array}$ \\
\hline 6 & Low & $\begin{array}{l}\text { Low chance the design control will detect a potential } \\
\text { cause of failure or subsequent failure mode }\end{array}$ \\
\hline 5 & Moderate & $\begin{array}{l}\text { Moderate chance the design control will detect a } \\
\text { potential cause of failure or subsequent failure mode }\end{array}$ \\
\hline 4 & Moderately high & $\begin{array}{l}\text { Moderately high chance the design control will detect } \\
\text { a potential cause of failure or subsequent failure mode }\end{array}$ \\
\hline 3 & High & $\begin{array}{l}\text { High chance the design control will detect a potential } \\
\text { cause of failure or subsequent failure mode }\end{array}$ \\
\hline 2 & Very high & $\begin{array}{l}\text { Very high chance the design control will detect a } \\
\text { potential cause of failure or subsequent failure mode }\end{array}$ \\
\hline 1 & Almost certain & $\begin{array}{l}\text { Almost certain chance the design control will detect a } \\
\text { potential cause of failure or subsequent failure mode }\end{array}$ \\
\hline
\end{tabular}

\section{1. $\quad$ Risk Identification}

Based on literature review and expert opinion, there are thirty risk criteria in three dimensions in company A, which are listed in Table 1.

\subsection{Risk Assessment}

FMEA technology is applied to the sustainable risk management of Baijiu supply chain. Experts scored the criteria based on Table 2-4. The results are shown in Table 8. The supply chain network is complex in company $\mathrm{A}$, and the risk factors are uncertainty. And the top ten the occurrence of risks are in Table 5, the top ten severity of risks are in Table 6, and the top ten the detection of risks are in Table 7. 


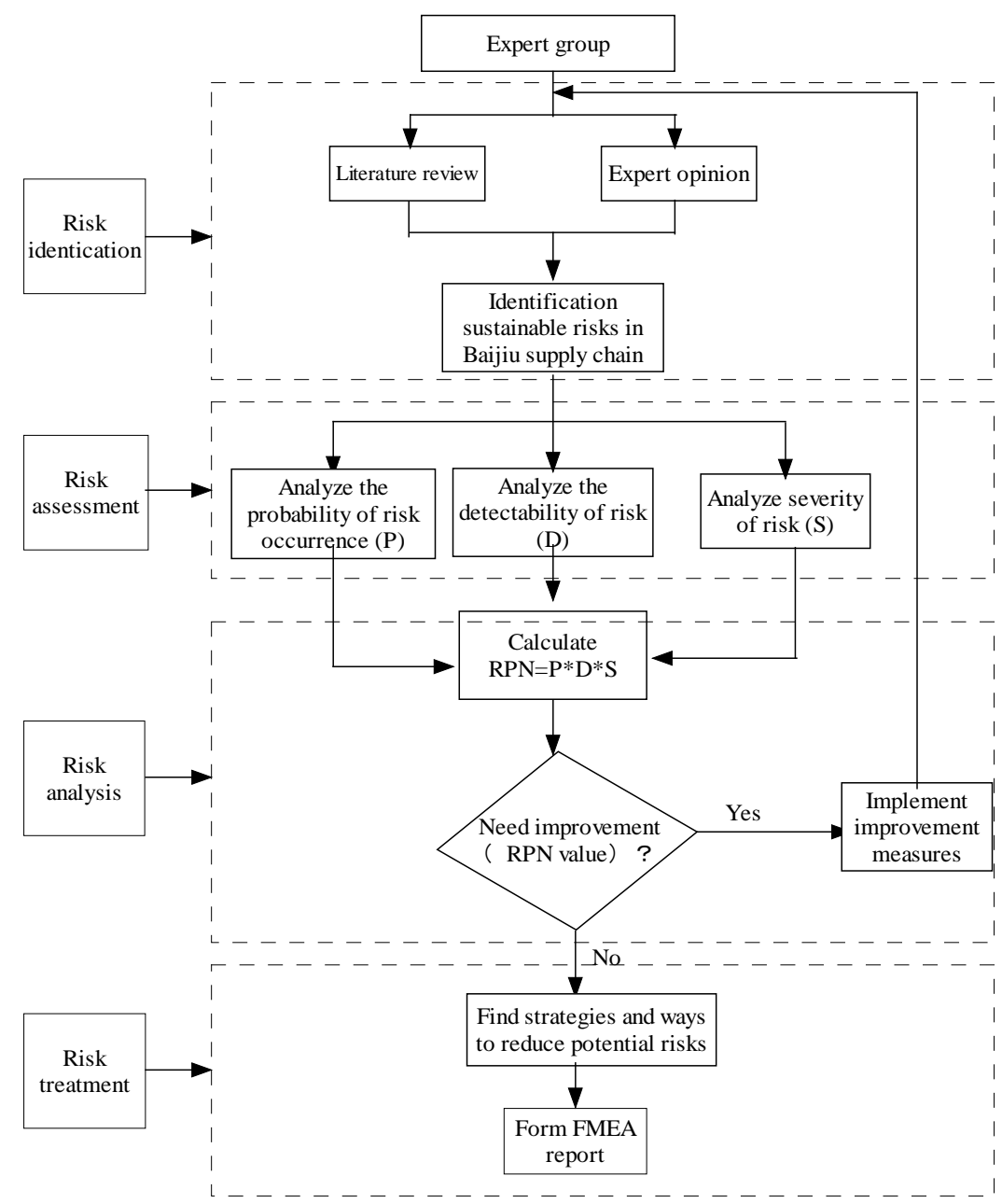

Fig 2: Risk management of sustainable supply chain in FMEA method.

Table 5: Ratings for the occurrence of a failure mode.

\begin{tabular}{ccc}
\hline Rating & Risk & Failure probability O \\
\hline 1 & Supply & 5.91 \\
2 & Globalization & 5.82 \\
3 & Information risk & 5.55 \\
4 & Demand volatility/fluctuations & 5.27 \\
5 & Logistics risk & 5.27 \\
6 & Partner risk & 5.27 \\
7 & Greenhouse gases/Carbon emissions & 5.00 \\
8 & Smog, heat wave, droughts & 5.00 \\
9 & Excessive working time & 4.91 \\
10 & Financial crisis & 4.64 \\
\hline
\end{tabular}


Table 6: Ratings for the severity of a failure mode.

\begin{tabular}{|c|c|c|c|}
\hline Rating & Risk & Severity & $\mathrm{S}$ \\
\hline 1 & Natural disaster & 8.09 & \\
\hline 2 & Environmental accidents & 7.91 & \\
\hline 3 & Product image risk & 7.55 & \\
\hline 4 & Product risk & 7.36 & \\
\hline 5 & Water quality risk & 7.36 & \\
\hline 6 & Pandemic & 7.18 & \\
\hline 7 & Boycott & 7.00 & \\
\hline 8 & Policy risk & 7.00 & \\
\hline 9 & Pollution & 6.91 & \\
\hline 10 & Carbon emissions & 6.82 & \\
\hline
\end{tabular}

Table 7: Ratings for the detective of a failure mode.

\begin{tabular}{ccc}
\hline Rating & Risk & Ease of detection D \\
\hline 1 & Natural disaster & 8.27 \\
2 & Moral hazard & 7.55 \\
3 & Culture risk & 7.45 \\
4 & Brand image risk & 7.45 \\
5 & Product risk & 7.36 \\
6 & Pandemic & 6.82 \\
7 & Policy risk & 6.64 \\
8 & Boycott & 6.27 \\
9 & Finance crisis & 6.00 \\
10 & Partnership risk & 5.82 \\
\hline
\end{tabular}

\subsection{Risk Analysis}

With the ratings of occurrence, severity, and ease of detection of the three dimensions, the results are in Table 8. And the top ten RPN is in Table 9. 
Table 8: Priority risk number for risk factors.

\begin{tabular}{|c|c|c|c|c|c|c|}
\hline Dimension & Risk & $\mathrm{O}$ & $\mathrm{S}$ & $\mathrm{D}$ & RPN & Ranking \\
\hline \multirow[t]{16}{*}{ Economic } & Price fixing accusations & 3.91 & 5.45 & 4.18 & 89.17 & 22 \\
\hline & Tax evasion & 4.09 & 5.55 & 4.09 & 92.81 & 19 \\
\hline & Boycotts & 3.09 & 7 & 6.27 & 135.72 & 14 \\
\hline & Supply volatility & 5.91 & 5.09 & 3.91 & 117.6 & 17 \\
\hline & Financial crisis & 4.64 & 6.73 & 6 & 187.14 & 5 \\
\hline & Legal risk/Litigations & 4.36 & 4.73 & 4.45 & 91.89 & 20 \\
\hline & Demand volatility & 5.27 & 6.18 & 5 & 162.98 & 11 \\
\hline & Product risk & 3.73 & 7.36 & 7.36 & 202.1 & 2 \\
\hline & Financial risk & 4 & 5.73 & 3.36 & 77.06 & 24 \\
\hline & Information risk & 4.36 & 6 & 7.55 & 197.55 & 3 \\
\hline & Partnership risk & 5.55 & 5.82 & 5.18 & 167.19 & 8 \\
\hline & Logistics risk & 5.27 & 6.18 & 5.82 & 189.64 & 4 \\
\hline & Management risk & 5.27 & 5.09 & 5.36 & 143.98 & 13 \\
\hline & Globalization & 4.55 & 6.27 & 4.73 & 134.79 & 15 \\
\hline & Mean & 5.82 & 5.91 & 4.82 & 165.65 & 9 \\
\hline & St deviation & 4.65 & 5.94 & 5.21 & 143.68 & \\
\hline \multirow[t]{10}{*}{ Environmental } & Environmental accidents & 0.83 & 0.725 & 1.215 & & \\
\hline & Pollution & 3.45 & 7.91 & 5.27 & 144.06 & 12 \\
\hline & Natural disasters & 3.64 & 6.91 & 4 & 100.5 & 18 \\
\hline & Smog, heat wave, droughts & 2.55 & 8.09 & 8.27 & 170.38 & 7 \\
\hline & Product waste & 5 & 5.09 & 3.55 & 90.25 & 21 \\
\hline & $\begin{array}{l}\text { Non-compliance with } \\
\text { sustainability laws }\end{array}$ & 4.18 & 4.82 & 3.64 & 73.27 & 26 \\
\hline & Carbon emissions & 3.73 & 6.82 & 2.91 & 73.93 & 25 \\
\hline & Water quality risk & 5 & 4.55 & 3.45 & 78.51 & 23 \\
\hline & Mean & 3 & 7.36 & 2.73 & 60.25 & 29 \\
\hline & St deviation & 3.82 & 6.44 & 4.23 & 98.89 & \\
\hline \multirow[t]{11}{*}{ Social } & $\begin{array}{l}\text { Unhealthy/dangerous } \\
\text { working environment }\end{array}$ & 0.877 & 1.421 & 1.809 & & \\
\hline & Unfair/Fair benefits & 3.18 & 6.73 & 2.73 & 58.38 & 30 \\
\hline & Excessive working time & 4.09 & 4.91 & 3.18 & 63.9 & 27 \\
\hline & Pandemic & 4.91 & 4.55 & 2.82 & 62.89 & 28 \\
\hline & Brand image risk & 2.73 & 7.18 & 6.82 & 133.55 & 16 \\
\hline & Policy risk & 3.09 & 7.55 & 7.45 & 173.86 & 6 \\
\hline & Cultural risk & 3.55 & 7 & 6.64 & 164.7 & 10 \\
\hline & Moral hazard & 4 & 6.91 & 7.45 & 206.02 & 1 \\
\hline & Mean & 3.65 & 6.4 & 5.3 & 123.81 & \\
\hline & St deviation & 0.741 & 1.177 & 2.26 & & \\
\hline & Mean overall & 4.14 & 6.19 & 4.97 & 125.66 & \\
\hline
\end{tabular}


Table 9: Ratings for the risk priority number (RPN).

\begin{tabular}{ccc}
\hline Rating & Risk & RPN \\
\hline 1 & Culture risk & 206.02 \\
2 & Product risk & 202.10 \\
3 & Moral hazard & 197.55 \\
4 & Partner risk & 189.64 \\
5 & Finance crisis & 187.14 \\
6 & Brand image risk & 173.86 \\
7 & Natural disaster & 170.38 \\
8 & Information risk & 167.19 \\
9 & globalization & 165.65 \\
10 & Policy risk & 164.70 \\
\hline
\end{tabular}

\subsection{Risk Treatment}

The last stage of risk management is to propose appropriate response strategies to reduce or eliminate risk factors. At this stage, the opinions of the eleven experts were fully respected. They provide four strategies: risk avoid, control, share and retain.According to Table 10, risk avoid and mitigation strategies are the most likely to used in Baijiu sustaianble supply chain risks.

Table 10: Risk treatment in Baijiu sustainable supply chain.

\begin{tabular}{lll}
\hline Dimension & Criteria & Risk response \\
\hline Economic & Price fixing accusations & Avoid \\
& & Mitigate \\
& Tax evasion & Retain \\
Boycotts & Avoid \\
& Mitigate \\
& Retain \\
& Financial crises & Mitigate \\
& Share \\
& Legal risk/Litigations & Mitigate \\
& Share \\
& Demand volatility/fluctuations & Avoid \\
& & Mitigate \\
& Mitigate \\
\end{tabular}




\begin{tabular}{|c|c|c|}
\hline & Product risk & Avoid \\
\hline & & Mitigate \\
\hline & Financial risk & Avoid \\
\hline & & Mitigate \\
\hline & Information risk & Avoid \\
\hline & & Mitigate \\
\hline & & Retain \\
\hline & Partnership risk & Avoid \\
\hline & & Mitigate \\
\hline & Logistics risk & Avoid \\
\hline & & Mitigate \\
\hline & Management risk & Avoid \\
\hline & & Mitigate \\
\hline & Globalization & Mitigate \\
\hline & & Retain \\
\hline Environmental & Environmental accidents & Avoid \\
\hline & & Mitigate \\
\hline & & Transfer \\
\hline & Pollution & Avoid \\
\hline & & Mitigate \\
\hline & Natural disasters & Mitigate \\
\hline & & Transfer \\
\hline & Smog, heat wave, droughts & Mitigate \\
\hline & & Transfer \\
\hline & Product waste & Avoid \\
\hline & & Mitigate \\
\hline & $\begin{array}{l}\text { Non-compliance } \\
\text { sustainability laws }\end{array}$ & Avoid \\
\hline & & Mitigate \\
\hline & Carbon emissions & Avoid \\
\hline & & Mitigate \\
\hline & Water quality risk & Avoid \\
\hline & & Mitigate \\
\hline Social & Unhealthy & Avoid \\
\hline & environment & Mitigate \\
\hline & Unfair/Fair benefits & Avoid \\
\hline & & Mitigate \\
\hline & Excessive working time & Avoid \\
\hline & & Mitigate \\
\hline & Pandemic & Avoid \\
\hline & & Mitigate \\
\hline & Brand image risk & Avoid \\
\hline & & Mitigate \\
\hline
\end{tabular}




$\begin{array}{ll}\text { Policy risk } & \text { Mitigate } \\ & \text { Retain } \\ \text { Cultural risk } & \text { Mitigate } \\ & \text { Transfer } \\ \text { Moral hazard } & \text { Avoid } \\ & \text { Mitigate }\end{array}$

\section{5. $\quad$ Results Discussions}

By using the FMEA method, each factor is scored by experts based on historical data and analysis. There are 30 risks from the three dimensions, 14 economic risks, eight environmental risks, and eight social risks.

As can be seen from Table 8, the average frequency of occurrence of sustainability-related risks is 4.20 . The average severity degree is 6.18 , and the average ease of detection is 4.97 . The average economic RPN is 139.84, which is the highest; the average environmental RPN value is 98.89, which is in the lowest. And the social average RPN is 132.61, which is in the middle. This is different from the existing research. Giannakis et al concluded that environmental risk is the highest, economy is second, and social risk is the last ${ }^{[3]}$. This is relevant to Chinese settings.

In terms of the situation, the liquor company in the case is a large-scale enterprise, and it has always attached great importance to environmental protection. It protects the legitimate rights and interests of employees. The sustainable supply chain of liquor companies needs to constantly improve and reduce the corresponding negative risks. Therefore, the risk response strategy should be fully tested. There are four risk treatment strategies in the real case: risk avoid, control, share and retain. In the case example, risk avoid and mitigation are the most used strategies in Baijiu sustaianble supply chain risk management.

\section{Conclusions}

Considering the economic, environmental and social risks faced by the Baijiu supply chain, thirty corresponding risk indicators were identified through literature analysis and expert opinions. The FMEA method was used to analyze the risk indicators. And the technology is applied to a real case study at a Baijiu company in Sichuan, China. The results show that the top five most important risks are culture risk, product risk, moral hazard, partnership risk and financial crisis, and the least important risks are unhealthy working conditions, water quality risk and excessive working time. The research method of this article can provide practical value for other Baijiu companies, and also provide value for the supply chains of other industries.

\section{Acknowledgements}

This work was supported by the National Natural Science Foundation of China (Nos.71772025, 71671118 and 71702156), the Humanities and Social Sciences of Ministry of Education of China (Nos.17YJC630098 and 19YJC630222), the Sichuan Science and Technology Program 
(No.2019JDR0026), the General Project of Sichuan Education Department (No.18SB0400), the Sichuan Provincial Education Department of Key Research Base Key Program (No.CJZ17-02), the Doctoral Fund Project of Sichuan University of Science and Engineering (Nos.2017RCSK21 and 2018RCSK01), and Sichuan Social Science Key Research Base Project (No.Xq18C07).

\section{References}

[1] Chen, P. S., \& Wu, M. T. (2013). A modified failure mode and effects analysis method for supplier selection problems in the supply chain risk environment: A case study. Computers \& Industrial Engineering, 66(4), 634-642

[2] Tang, C. S. (2006). Perspectives in supply chain risk management. International journal of production economics, 103(2), 451-488.

[3] Giannakis, M., \& Papadopoulos, T. (2016). Supply chain sustainability: A risk management approach. International Journal of Production Economics, 171, 455-470.

[4] Zheng, X. W., Han, B. Z. (2016). Baijiu, Chinese liquor: history, classification and manufacture. Journal of Ethnic Foods, 3(1), 19-25.

[5] Zou, W., Ye, G., Zhang, K. (2018). Diversity, Function, and Application of Clostridium in Chinese Strong Flavor Baijiu Ecosystem: A Review. Journal of food science, 83(5), 1193-1199.

[6] Blackburn, W. R. (2012). The sustainability handbook: The complete management guide to achieving social, economic and environmental responsibility. Routledge.

[7] Cousins, P. D., Lamming, R. C., \& Bowen, F. (2004). The role of risk in environment-related supplier initiatives. International Journal of Operations \& Production Management, 24(6), 554-565.

[8] Anderson, D. R., \& Anderson, K. E., (2009). "Sustainability risk management”, Risk Management and Insurance Review, 12(1), 25.

[9] Foerstl, K., Reuter, C., Hartmann, E., \& Blome, C. (2010). Managing supplier sustainability risks in a dynamically changing environment-Sustainable supplier management in the chemical industry. Journal of Purchasing and Supply Management, 16(2), 118-130.

[10] Hofmann, H., Busse, C., Bode, C., \& Henke, M., (2014). Sustainability - related supply chain risks: Conceptualization and management, Business Strategy and the Environment,23(3), 160-172.

[11] Pullman, M. E., Maloni, M. J., \& Carter, C. R., (2009). Food for thought: social versus environmental sustainability practices and performance outcomes, Journal of Supply Chain Management, 45(4), 38-54.

[12] Un Global Compact., (2010). Supply chain sustainability: A practical guide for continuous improvement", Sustainability the Journal of Record, 4(3), 480-497(18)

[13] Kolich, M., (2014). Using Failure Mode and Effects Analysis to design a comfortable automotive driver seat, Applied ergonomics, 45(4), 1087-1096.

[14] Feili, H. R., Akar, N., Lotfizadeh, H., Bairampour, M., \& Nasiri, S., (2013). Risk analysis of geothermal power plants using Failure Modes and Effects Analysis (FMEA) technique, Energy Conversion and Management, 72, 69-76.

[15] Silva, M. M., de Gusmão, A. P. H., Poleto, T., e Silva, L. C., \& Costa, A. P. C. S. , (2014). A multidimensional approach to information security risk management using FMEA and fuzzy theory, International Journal of Information Management,34(6), 733-740.

[16] Dağsuyu, C., Gö̧̧men, E., Narll, M., \& Kokangül, A., (2016). Classical and fuzzy FMEA risk analysis in a sterilization unit,Computers \& Industrial Engineering, 101, 286-294. 